\title{
Impact of World Heritage Declaration on Guangzhou Residents' Sense of Place
}

\author{
Wen JIAN \\ The Affiliated High School of SCNU, Guangzhou, China \\ 731939402@qq.com
}

Keywords: Sense of place, World heritage declaration, Maritime Silk Road, Guangzhou.

\begin{abstract}
This paper investigates Guangzhou residents' sense of place, focusing on the impact of world heritage declaration as an external event by using a five-point Likert-type scale with a series of statements listed. We have found that Guangzhou's world heritage declaration has strengthened residents' place identity, place dependence, natural environment perception as well as social cultural perception. Furthermore, the more the residents are educated, the greater interest in the cultural heritage of Guangzhou they have; those who are more interested in the cultural heritage of Guangzhou have stronger sense of place, and are more likely to feel that they have special connections with Guangzhou. Besides, the longer they have lived in Guangzhou, the more they believe that world heritage declaration strengthens their place identity, as well as their sense of belonging and place rootedness.
\end{abstract}

\section{Introduction}

Since the establishment of Qin Dynasty, Guangzhou, a crucial port and commercial city in China, has had economic circulation, trade flows, technical and cultural exchange, and peaceful intercourse with countries in Asia, Europe, Africa and America for 2200 years. Being a bridge between Chinese and western civilizations, Guangzhou is a living fossil that has witnessed the rise and fall of Maritime Silk Road. With dozens of historical sites, however, Guangzhou does not have a UNESCO-recognized world cultural heritage. Currently, 6 historical relics in Guangzhou, together with some relics in other cities, are placed on the list of world cultural heritage application in the name of Maritime Silk Road relics. Whether a world heritage declaration in Guangzhou will influence residents' sense of place is a question worth studying.

Sense of place is the emotional attachment of human to a place, and it is one of the core concepts of environmental psychology. Recent researches on Guangzhou residents' sense of place mainly relate to the migrants in the urban villages in Guangzhou city, tourists in historic and cultural blocks of Guangzhou, and African immigrants in Christian places in Guangzhou. For instance, Hong Zhu (2016) conducted a research on a sample of 412 migrants from three urban villages in Guangzhou city and found that the sense of place affects the social cohesion indirectly by the factors of rootedness, living condition and culture capital [1]. Dixiang Xie (2014) taking the Lizhiwan Stream in historic and cultural blocks of Guangzhou as an example, analyzed the features of the tourists' sense of place from four dimensions, including landscape environment, social humanity, tourist function and local attachment with a quantitative research method [2]. Jialing Huang (2014) focused on the underlying mechanism and the determinants of African immigrants' sense of place in religious space in Guangzhou, using the Sacred Heart Cathedral as a study area [3]. Junxi Qian (2012) argued that Massey's theory of a global sense of place needs to include a dimension concerning how concrete subject positions can be negotiated and challenged in the imagination of place by using a case study of the place politics in Xiaozhou Village, Guangzhou[4]. Nevertheless, no research centers on the declaration of world heritage's influence on Guangzhou citizens' sense of place. Therefore, this paper aims to perform an empirical research on the influence exerted by the world cultural heritage declaration of Maritime Silk Road on sense of place of Guangzhou residents. 


\section{Method}

\section{Questionnaire Construction}

The questionnaire comprised three parts. The first part was the personal information such as gender, age, educational background, occupation and years living in Guangzhou city. The second section (Table 1) measured Guangzhou residents' perception about the changes in themselves and the community brought by the world heritage declaration (WHD) with 10 statements listed, based on the questionnaire of Zhang [5] and Gu[6]. The third section (Table 2) of the questionnaire measured the citizens' sense of place, which was comprised of place identity, place dependence, perception of natural environment and perception of social cultural with 14 statements listed, based on the questionnaire of Zheng[7] and Williams[8]. Degree of agreement with the 24 statements were elicited through the use of a five-point Likert-type scale with 1 being the lowest score ('very strongly disagree') to 5 ('very strongly agree') being the highest.

Table 1. Residents' Perception about the Changes after WHD in Guangzhou

\begin{tabular}{|c|c|c|}
\hline Items & Mean & $\begin{array}{c}\text { Standard } \\
\text { Deviation }\end{array}$ \\
\hline I'm interested in the cultural heritage of Guangzhou. & 4.62 & 0.58 \\
\hline $\begin{array}{c}\text { I know that Maritime Silk Road in Guangzhou is applying for } \\
\text { UNESCO world heritage. }\end{array}$ & 4.48 & 0.76 \\
\hline $\begin{array}{c}\text { I know there are 6 historic sites in Guangzhou applying for the world } \\
\text { heritage; They are The Western Han Dynasty Mausoleum of the } \\
\text { Nanyue King, God Temple of South Sea, Nanyue King Palace, } \\
\text { Guangxiao Temple, Huaisheng Mosque, Xianxian Mosque. }\end{array}$ & 4.40 & 0.82 \\
\hline $\begin{array}{c}\text { Owing to the WHD, the popularity of Guangzhou historic sites } \\
\text { increased. }\end{array}$ & 4.72 & 0.53 \\
\hline $\begin{array}{c}\text { Renovation brought by WHD improved the environment } \\
\text { surrounding historic sites. }\end{array}$ & 4.65 & 0.58 \\
\hline $\begin{array}{c}\text { WHD let me realize that Guangzhou is of great value as a historical } \\
\text { and cultural city. }\end{array}$ & 4.70 & 0.52 \\
\hline WHD Enhanced my sense of identity and belonging to Guangzhou. & 4.62 & 0.61 \\
\hline I have growing love for Guangzhou. & 4.59 & 0.62 \\
\hline WHD made me pay more attention to the development of \\
Guangzhou in the future. & 4.55 & 0.65 \\
\hline A successful World Heritage application will make me feel proud. & 4.61 & 0.65 \\
\hline
\end{tabular}

Note: five-point Likert-type scale with ' 5 '= 'very strongly agree', '4'= 'agree', ' 3 '= 'unclear' ' '2'= 'disagree', ' 1 '= 'very strongly disagree'.

\section{Characteristics of the Samples}

Data were collected through an online questionnaire website (http://www.sojump.com/) with a total of 319 respondents. The statistical results show: women participants in the questionnaire survey were slightly more than their male counterparts $(59.56 \%)$; The majority $(73.99 \%)$ of respondents aged 30 years old or older; $75.24 \%$ of them had bachelor degree or above; those living in Guangzhou for more than 10 years accounted for $67.71 \%$; Staff working in enterprises and institutions took up $68.02 \%$. The results are shown in Table 1 and Table 2. 
Table 2. The Measurement of Influence on Guangzhou Residents' Sense of Place

\begin{tabular}{|c|c|c|c|}
\hline Dimensions & Items & Mean & $\begin{array}{l}\text { Standard } \\
\text { Deviation }\end{array}$ \\
\hline \multirow{4}{*}{$\begin{array}{l}\text { Place } \\
\text { Identity }\end{array}$} & $\begin{array}{l}\text { After a successful application for World Heritage, } \\
\text { Guangzhou will be more significant to me. }\end{array}$ & 4.39 & 0.82 \\
\hline & WHD raised my sense of attachment to Guangzhou. & 4.38 & 0.76 \\
\hline & WHD enhanced my identity of Guangzhou. & 4.49 & 0.69 \\
\hline & $\begin{array}{c}\text { I feel that I have a special connection with Guangzhou } \\
\text { owing to the WHD. }\end{array}$ & 4.34 & 0.82 \\
\hline \multirow{5}{*}{$\begin{array}{c}\text { Place } \\
\text { Dependence }\end{array}$} & I think there is no other place better than Guangzhou. & 3.83 & 1.14 \\
\hline & $\begin{array}{l}\text { Guangzhou is more suitable for my residence than } \\
\text { anywhere else. }\end{array}$ & 4.10 & 0.95 \\
\hline & $\begin{array}{l}\text { Living in Guangzhou is more satisfying than living in other } \\
\text { places. }\end{array}$ & 4.14 & 0.92 \\
\hline & I feel more inseparable from Guangzhou after WHD. & 3.92 & 1.05 \\
\hline & I'll not move out of Guangzhou without special reasons. & 4.07 & 0.97 \\
\hline \multirow{2}{*}{$\begin{array}{l}\text { Perception of } \\
\text { Natural } \\
\text { Environment }\end{array}$} & $\begin{array}{l}\text { WHD made me integrated with the historical sites of } \\
\text { Guangzhou. }\end{array}$ & 4.05 & 0.98 \\
\hline & $\begin{array}{l}\text { WHD brought me a strong awareness of protecting the } \\
\text { surrounding environment owing to the world heritage } \\
\text { declaration. }\end{array}$ & 4.35 & 0.77 \\
\hline \multirow{3}{*}{$\begin{array}{l}\text { Perception of } \\
\text { Social } \\
\text { Culture }\end{array}$} & $\begin{array}{l}\text { WHD increased my sense of belongingness and place } \\
\text { rootedness to Guangzhou. }\end{array}$ & 4.25 & 0.84 \\
\hline & $\begin{array}{l}\text { The cohesion of Guangzhou residents has become stronger } \\
\text { as a result of their participation in the work of WHD. }\end{array}$ & 4.16 & 0.90 \\
\hline & My happiness enhanced due to WHD. & 4.04 & 0.96 \\
\hline
\end{tabular}

Note: five-point Likert-type scale with '5'= 'very strongly agree', '4'= 'agree', '3'= 'unclear', '2'= 'disagree', ' 1 '= 'very strongly disagree'.

\section{Discussion}

Sense of place plays a very important role in shaping and maintaining the individual or collective identity. Positive sense of place makes people feel that they belong to the local and local also belong to them, but negative sense of place makes people lack a sense of belonging. A lack of sense of place among residents leads to a lack of enthusiasm for participation in community construction [9]. Sense of place also helps people achieve their goals and self-regulate, and enhance their self-esteem and self-identity. In addition, sense of place can maintain the continuity and stability of population in a certain area, and is conducive to the long-term stay and development of people [10].

In general, the mean scores of Likert scale as 1-2.4, 2.5-3.4 and 3.5-5 indicate negative, neutral, and positive result respectively. The mean of the 14 items in the questionnaire survey which was used to measure the influence of WHD on Guangzhou residents' sense of place is above 3.8. This presentation divides sense of place into 4 elements: place identity (emotional attachment), place dependence (functional attachment), natural environment perception and social cultural perception. Based on the questionnaire results in Table 1 and table 2 and interview results, we analyzed the influence of WHD and personal information on the 4 aspects of residents' sense of place. 


\section{Influence of WHD on Guangzhou Residents' Sense of Place}

\section{Influence on Residents' Place Identity}

Place identity is a kind of emotional attachment. It refers to an individual's intentional or unintentional thoughts about objective environment in order to achieve her or his emotional attachment and sense of belonging through a combination of her or his attitudes, beliefs, preferences, feelings, values, purposes, meanings and behavior tendencies [11].

In the process of WHD, Guangzhou municipal government has launched a series of activities of compiling books and videos, holding treasures exhibitions etc. These activities encourage residents to know about Guangzhou further. Most residents believe that WHD increases the popularity of Guangzhou historic sites (75.24\% 'very strongly agree' and $22.57 \%$ 'agree'), makes me realize Guangzhou is of great value as a historical and cultural city ( $71.79 \%$ 'very strongly agree' and 26.65\% 'agree'), enhances my sense of identity and belonging to Guangzhou (68.34\% 'very strongly agree' and $26.33 \%$ 'agree'), and increases my love to Guangzhou (64.58\% 'very strongly agree' and 31.03\% 'agree'). Additionally, residents tend to believe and feel proud of that Guangzhou not only is a place for generations of Cantonese to live in, but also has treasures of world cultural heritage $(68.03 \%$ 'very strongly agree' and $26.33 \%$ 'agree').

As some of the main subjects involved in the WHD, residents feel that they have a special connection with Guangzhou, and their sense of identity and attachment to Guangzhou has been enhanced. Obviously, WHD strengthens residents' emotional attachment to Guangzhou and their place identity.

\section{Influence on Residents' Place Dependence}

Place dependence is a kind of functional attachment. It refers to the users' dependence on a particular environment or facility when they perform a particular activity. That is, a certain physical function can only be provided in such a unique environment or facility [12].

In recent years, Guangzhou municipal government has renovated the surrounding environment of God Temple of South Sea, Guangxiao temple and other historical sites, and built 'Guangzhou Maritime Museum' and 'Guangzhou commercial Museum' to preserve the Guangzhou Maritime Silk Road historical atmosphere and environmental features. Among the changes brought by WHD, the strongest perception of residents is roads construction and renovation of surrounding environment of historical sites. They think that thanks to the WHD, the surrounding environment are thoroughly improved (69.59\% 'very strongly agree' and 26.96\% 'agree'); many of them will not move out of Guangzhou (37.62\% 'very strongly agree' and $28.21 \%$ 'agree'), and living in Guangzhou is more satisfying than living in somewhere else (42.01\% 'very strongly agree' and $36.68 \%$ 'agree').

Residents are keenly aware of the changes brought by the WHD, and their place dependence on Guangzhou has also been strengthened. However, since the benefits to Guangzhou residents bought by the WHD are not very clear, the influence on their place dependence is less than that on their place identity.

\section{Influence on Residents' Perception of Natural Environment}

During the process of the WHD, residents' awareness of the value of historical sites in Guangzhou has increased and their sense of pride has been enhanced through media and communications. They feel that they merged with the historical sites of Guangzhou (40.44\% 'very strongly agree' and 32.92\% 'agree'), recognized the historical value of Guangzhou City, and gradually produced a strong awareness of protection of the surrounding environment (49.84\% 'very strongly agree' and $38.56 \%$ 'agree').

\section{Influence on Residents' Perception of Social Culture}

In the process of the WHD, residents of Guangzhou cooperated with the government in relocating as well as renovating houses and environment, and boosted their sense of belongingness and place 
rootedness to Guangzhou (45.77\% 'very strongly agree' and $38.24 \%$ 'agree'). Meanwhile, the cohesion and happiness of Guangzhou residents has grown on account of their participation in the work of WHD.

\section{Influence of Personal Information on Sense of Place}

\section{Impact of Educational Background}

The better their academic qualifications are, the greater interest in the cultural heritage of Guangzhou they have: $77.97 \%$ of the respondents with graduate degree or above chose 'very strongly agree' while $50 \%$ of them with high school or fewer academic qualifications opted for 'very strongly agree'. Moreover, the better their educational backgrounds are, the more they understand that the WHD makes Guangzhou, a historical and cultural city, of greater value: $75 \%$ of the participants with bachelor degree or above picked 'very strongly agree' while $50 \%$ of those secondary-school-educated selected 'very strongly agree'. Further, the more educated they are, the stronger awareness of protecting the surrounding environment they have: $56.35 \%$ of those with bachelor degree or above opted for 'very strongly agree' while $25 \%$ of the junior high school educated respondents chose 'very strongly agree'.

\section{Impact of Age}

The selections of some items vary at different ages. Shown in Table 3, respondents under the age of 18 are not very interested in Guangzhou cultural heritage and the enhancement of their sense of place is weaker than that of other age groups.

Table 3 Proportion of 'very strongly agree' on part of items in different ages

\begin{tabular}{|l|l|l|l|l|l|}
\hline \multicolumn{1}{|c|}{ Items } & $<18$ & $18-30$ & $30-45$ & $45-60$ & $>60$ \\
\hline $\begin{array}{l}\text { Interests in the cultural heritage of } \\
\text { Guangzhou }\end{array}$ & $37.78 \%$ & $71.05 \%$ & $69.23 \%$ & $71.84 \%$ & $81.25 \%$ \\
\hline $\begin{array}{l}\text { WHD let me know that Guangzhou is of } \\
\text { great value as a historical and cultural city. }\end{array}$ & $55.56 \%$ & $73.68 \%$ & $74.36 \%$ & $72.82 \%$ & $87.5 \%$ \\
\hline $\begin{array}{l}\text { WHD brought me a strong awareness of } \\
\text { protecting the surrounding environment. }\end{array}$ & $20 \%$ & $52.63 \%$ & $52.14 \%$ & $53.4 \%$ & $87.5 \%$ \\
\hline $\begin{array}{l}\text { Guangzhou is more suitable for my } \\
\text { residence than anywhere else. }\end{array}$ & $26.67 \%$ & $42.11 \%$ & $46.15 \%$ & $42.72 \%$ & $68.75 \%$ \\
\hline
\end{tabular}

\section{Impact of Years of Living in Guangzhou}

The longer the residents have lived in Guangzhou, the more they believe that the WHD strengthens their place identity, sense of belonging and place rootedness; residents living in Guangzhou for 1-5 years have the worst identification.

Also, we have found that the more interested the residents are in the cultural heritage of Guangzhou, the stronger sense of place they have, and the more they feel that the WHD makes them connected with Guangzhou in a special way.

\section{Conclusion}

This study demonstrates that Guangzhou's world heritage declaration, as a special and important external event, has strengthened the sense of place of local residents. The WHD has reconstructed the local economy, politics, natural environment, and cultural environment etc. Consequently, the local residents' perception to the natural, social and cultural changes enhanced their place identity and place dependence.

In the meantime, we can see that although residents' sense of place has been strengthened, they are still lacking awareness of active protection. Residents under the age of 18 are generally not very 
interested in Guangzhou cultural heritage, and their sense of place is strengthened less than other age groups'. Hence it is necessary to establish a linkage mechanism between the WHD and the benefits of residents so that the residents can become active protectors of world cultural heritage, and to educate youngsters about Guangzhou's history and culture so that the next generations would be able to become active inheritors of Guangzhou's cultural heritage.

\section{References}

[1] H.Zhu, R.Li, B.Y.Su, The migrants' sense of place and its influencing factors on a microcosmic perspective: a case study of the migrants in the urban villages in Guangzhou, Acta Geographica Sinica, 71 (2016) 637-648.

[2] D.X.Xie, J.Chang, X.M.Zhu, X.Chen, Sense of place of the tourists to historical and cultural blocks: a case study of the Lizhiwan Stream, Guangzhou, Tropical Geography, 34 (2014) 482-488.

[3] J.L.Hang, S.J.He, Profile and determinants of African immigrants' sense of place in religious space: a case study of Guangzhou Sacred Heart Cathedral, Tropical Geography, 34 (2014) 308-318.

[4] J.X.Qian, L.Y.Qian, H. Zhu, Subjectivity, modernity, and the politics of difference in a periurban village in China: towards a progressive sense of place? Environment and Planning D-society \& space, 30 (2012) 1064-1082.

[5] C.Z.Zhang, Y.Wang, Applying for world heritage and local residents' cognition of heritage values: a perspective of social representation-based on the case study of Kaiping Diaolou and Villages, Tourism Tribune, 24 (2009) 43-47.

[6] H.M.Gu, C.Ryan, Place attachment, identity and community impacts of tourism-the case of a Beijing hutong, Tourism Management, 29 (2008) 637-647.

[7] Q.M.Zheng, Z.C.Xia, W.B.Lou, Y.Y.Liu, The impact of world heritage declaration on residents' sense of place: a case study of Mount Lang, Tourism Sci., 28 (2014) 54-64.

[8] D.R.Williams, J.W.Roggenbuck, Measuring place attachment: some preliminary results, Leisure Research Symposium of National Recreation and Park Association Adington, October 20-22. http://www.fs.fed.us/rm/value/docs/nrpa89.pdf

[9] M.Billing. Sense of place in the neighborhood, in locations of urban revitaliazation, GeoJournal, 64 (2005) 117-130.

[10] D.Butz, J.Eyles, Re-conceptualizing sense of place: social relations, ideology and ecology, Human Geography, 79 (1997) 1-25.

[11] H.M.Proshansky, The city and self-identity, Environment \& Behavior, 10(1978) 147-169.

[12] D.R.Williams, M.E.Patterson, Snap shots of what, exactly? A comment on methodological experimentation and conceptual foundations in place research, Society \& Natural Resources, 20 (2007) 931-937. 